\title{
Mental distress, perceived need, and barriers to receive professional mental health care among university students in Ethiopia
}

Assegid Negash*, Matloob Ahmed Khan, Girmay Medhin, Dawit Wondimagegn and Mesfin Araya

\begin{abstract}
Background: There is limited evidence on the extent of the perceived need and barriers to professional mental health service delivery to university students with mental distress in low- and middle-income countries (LMICs). This study was designed to assess the prevalence of mental distress, perceived need for professional mental health care and barriers to the delivery of services to affected undergraduate university students in Ethiopia.

Methods: A multi-stage sampling technique was used to recruit 1135 undergraduate university students. Symptoms of mental distress were evaluated using the Self-Reported Questionnaire (SRQ-20) and a score of above seven was used to identify positive cases. The perceived need for professional mental health care was assessed using a single 'yes or no' response item and barriers to mental health care were assessed using Barriers to Access to Care Evaluation (BACE30) tool. Percentage, frequency, mean, and standard deviation were employed to summarize demographic characteristics of the participants and to identify common barriers to mental health care service. Moreover, the association of demographic variables with total mean scores of BACE-III sub-scales was modeled using multiple linear regression.
\end{abstract}

Results: The prevalence of mental distress symptoms was 34.6\% and the perceived need for professional mental health care was $70.5 \%$ of those with mental distress. The top five barriers to receiving professional mental health service were (a) thinking the problem would get better with no intervention, (b) being unsure where to go to get professional help, (c) wanting to solve the problem without intervention, (d) denying a mental health problem existed, and (e) preferring to get alternative forms of mental care. Coming from a rural background, being a second and fourthyear student, and a family history of mental illness were significantly associated with barriers to receive professional mental health service.

Conclusion: The high prevalence of mental distress, the paucity of mental health care, and the report of barriers to access what professional mental health care there is among Ethiopian undergraduate students is a call to address the disparity.

Keywords: Mental distress, Perceived need, Barrier, Professional mental health care, Ethiopia, Undergraduate students

\footnotetext{
* Correspondence: assegidn@gmail.com

Department of Psychiatry, College of Health Sciences, School of Medicine

Addis Ababa University, Addis Ababa, Ethiopia

(c) The Author(s). 2020 Open Access This article is licensed under a Creative Commons Attribution 4.0 International License, which permits use, sharing, adaptation, distribution and reproduction in any medium or format, as long as you give appropriate credit to the original author(s) and the source, provide a link to the Creative Commons licence, and indicate if changes were made. The images or other third party material in this article are included in the article's Creative Commons licence, unless indicated otherwise in a credit line to the material. If material is not included in the article's Creative Commons licence and your intended use is not permitted by statutory regulation or exceeds the permitted use, you will need to obtain permission directly from the copyright holder. To view a copy of this licence, visit http://creativecommons.org/licenses/by/4.0/ The Creative Commons Public Domain Dedication waiver (http://creativecommons.org/publicdomain/zero/1.0/) applies to the data made available in this article, unless otherwise stated in a credit line to the data.
} 


\section{Background}

Mental distress is among the most common type of experience that accompanies mental health problem characterized by a mixture of different complaints such as feeling sad, worried, tense or angry [1]. Common mental disorders are a collective noun for anxiety, depression, and somatoform disorders that can adversely affect individuals across the world $[2,3]$. According to the World Health Organization [4] 2015 report, over 300 million (4.4\%) and 264 million (3.6\%) of the total word population are estimated to suffer from anxiety and depression, respectively [5]. In particular, the contribution of these disorders to the global mental health burden from lowand middle-income countries (LMICs) is high [6]. However, the accessibility of mental health service is still very low, which accounts for the 76-85\% treatment gap [7]. This gap has been linked to the lack of skilled human resources, lack of mental health policies, lack of access to mental health services, poverty, the preference for informal treatments, a lack of mental health literacy, the fear of stigma, and a low commitment from funders to access the services [8-12]. As a result, the majority of people living with anxiety and depression in LMICs do not receive professional mental health care [13].

As in any other LMICs, the prevalence and burden of anxiety and depression in Ethiopia is high. For example, a systematic review and meta-analysis study reported that the pooled prevalence of these disorders is $22 \%$ [14], which is associated with risk factors such as food insecurity [15], poverty, violence, migration, and substance use [16]. The burden of depression alone contributes to about $6.5 \%$ of the burden of diseases [16], however, as noted above few people are able to receive formal mental health services. Evidence showed that the pooled prevalence of help-seeking behaviors of people with depression is 38\% [17]. In Ethiopia, most people with mental illness first contact non-professional care providers such as religious leaders and herbalists [18]. But, if the patient remains affected, he/she will go to western trained psychiatric care providers [18]. The psychiatric services are mainly concentrated in the capital city of Ethiopia, Addis Ababa [19].

To scale-up the limited mental health services across the country, the government of Ethiopia has planned to expand $100 \%$ of mental health care by 2020 [20]. The National Mental Health Strategy was developed in 2012 by the Federal Ministry of Health aimed to decentralize and integrate mental health services at the primary health care level [19]. At the university level, mental health services have been established to support students with mental health problems, although the quality of the service provided is under question. Currently, Ethiopia has 45 public universities, where 392,788 (255,657 male and 137,131 female) undergraduate students enrolled in
2017. These students are adolescents, economically dependent on their family and full-time learner, they came from rural-urban backgrounds with diversified cultures, languages, and ethnicity.

The prevalence of mental distress is high among university students [21]. A cross-cultural web-based survey of 17,348 university students from 23 high-middle-and lowincome countries reported that the average depression prevalence is $20 \%$ [22]. Another study also reported that the prevalence of depression and anxiety is 68.5 and $54.4 \%$, respectively [23]. Similarly, the prevalence of these disorders ranges from $21.6-49 \%$ among Ethiopian university students $[24,25]$. This high prevalence is associated with several factors including: (i) vulnerability of adolescence age for early onset of mental distress [26]; (ii) new identity formation [27]; (iii) challenges of being away from home for the first time [28]; and (iv) academic pressure, substance use [29], and financial difficulties [30]. Moreover, family histories of mental illness, conflicts with friends, not attending religious services, and being freshman are risk factors for mental distress among university students in Ethiopia [31, 32]. On the other hand, having high social support and enough pocket money are protective factors from mental distress [32].

Mental distress has a negative impact on university students' academic performance [29]. Evidence shows that mentally distressed students scored poor examination result compared with non-distressed students [33]. Although mental distress has such impact, the treatment gap remains large ranging from 37 to $84 \%$ [34]. This treatment gap is also high among Ethiopian university students, where majority of the students receive treatment from informal sources such as family, friends, relatives, and religious leaders [35]. There are several barriers that hinder students with mental distress from receiving mental health services. Among these: (i) receiving help from friends or family; (ii) preferring to manage mental illness by self; (iii) normalizing mental illness; (iv) thinking that mental illness would get better by itself [36]; (v) lack of perceived need; (vi) being unaware of the existence of professional mental health services; (vii) fear of stigma, concerns about privacy; (viii) skepticism about treatment effectiveness; (iv) socio-economic problem [34]; and ( $\mathrm{x}$ ) denying mental illness [37].

There are associations between demographic variables and perceived need for mental health care. Female students have more positive attitudes to the utilization of mental health services compared with male students; the possible explanations could be that women experience more mental distress and they give more value for support received from professionals [38]. Conversely, male students are more likely to seek mental health care compared with female students; this might be caused by the interaction effect of other demographic variables in the 
analysis model [39]. Despite this, there is a finding reporting gender is not a predictor for seeking mental health care; possibly this is caused by insignificance gender difference in mean scores of depression and selfesteem [40]. Likewise, there is no gender difference in reporting barriers to receive mental health care [41]. Older students are more likely to have positive attitudes toward seeking mental health care than younger students; possibly caused by the past mental health care received [42]. Adolescents have a more positive attitude to seek mental health care than adults, because adolescents had more confidence in and better experience of using modern mental health care [39]. There are also insignificant difference in reporting barriers to access mental health care based on age [41].

Class years, family history of mental illness, and substance use are also reported as predictors to receive mental health care. For instance, first and fourth-years students are less likely to use mental health services compared with second and third-years students [43], although there is no change based on rural-urban backgrounds [44]. However, students who had personal contact with someone with a history of mental illness were significantly associated with decreased help-seeking intention; this could be possibly due to the negative experiences students had with a person who they know to have a mental illness [45]. Moreover, students with mental distress use substances to manage feeling of discomfort, which might hinder their interest or preparedness in seeking mental health care [46]. Mental distress, predictors, and barriers to receiving mental health care among university students occur globally, however, there might be higher prevalence, more complex stressors, lower help-seeking behaviors, and a higher treatment gap in LMICs compared with developed countries [47]. For example, even if the prevalence of mental distress is high among university students in LMICs, the majority of them do not receive professional mental health care $[48,49]$.

Most studies conducted in Ethiopian universities are primarily focused on assessing the prevalence of mental distress rather than looking at the possible barriers to receiving professional help. Besides of this, there is a literature gap with regard to identifying the perceived need for mental health service and demographic factors associated with barriers to receive mental health care among university students in Ethiopia. Therefore, this current study is aimed to assess the prevalence of mental distress, perceived need, and identify common barriers to receive professional mental health care among undergraduate students in Wolaita Sodo University (WSU). Our study also investigated the demographic predictors of the barriers to mental health care. The current study findings will fill the literature gap on professional help- seeking intention, predictors, and barriers to receive mental health service among undergraduate students in LMICs. Besides this, our findings inform to adapt and study feasibility of psychological intervention for students with mental distress within Ethiopian universities with potential implication for other LMICs universities.

\section{Methods}

\section{Study setting}

The current study is conducted at WSU, a public university located in the Sodo town of Wolaita Sodo Zone, Southern Nations, Nationalities, and Peoples' Regional State (SNNPR) of Ethiopia. Sodo town is located $320 \mathrm{~km}$ south of Addis Ababa. WSU was established in 2007 as a result of the rapid expansion of higher education in Ethiopia. The university began with an intake of 801 students (609 males and 192 females) in four faculties and sixteen departments. Currently, the university runs undergraduate and graduate programs in six colleges and five schools. During the study period, a total of 12 , 028 (7321males and 4707 females) undergraduate students were registered. These students qualify to join the university by taking the Grade 12 national entrance examination prepared by Ministry of Education. WSU has two counseling offices and two health centers. There are three psychologists in the counseling offices that provide counseling services for students with mental health problems. The two health care centers are the Ottona hospital and the students' clinic, both of which provide health care services. Ottona hospital is a referral hospital that provides health care services for the community and for the students with severe mental health problem by providing medication.

\section{Study design, objectives and study period}

An institution-based cross-sectional survey was conducted among WSU undergraduate students from December 2017 to January 2018. The objective was to estimate the prevalence of mental health problems, perceived need, and to identify barriers and demographic predictors to receive professional mental health care.

\section{Sample size}

A sample size of 1135 was estimated with an assumed prevalence rate of mental distress $40.9 \%$ [32], precision of $\pm 3,95 \%$ confidence interval, and $10 \%$ non-response considered. For the other two objectives (perceived need and barriers to receive mental health care) separate sample sizes were not estimated. All the participants who were screened positive for mental distress $(>7)$ were used as the denominator to estimate the proportion of students having a perceived need for professional mental health care. Those participants who had mental distress symptoms and who did not receive mental health 
services from professionals in the past 3 months were eligible to be part of the study.

\section{Sampling and procedures}

A stratified multi-stage sampling technique was used to recruit study participants. A list of students' names from all first to fifth years was obtained from the registrar office of WSU. The first participant's name was selected randomly; the remaining participants were selected using systematic random sampling. To accomplish, the first step was stratifying undergraduate students by their schools/colleges (six colleges and five schools). For the second step, the total sample size was allocated into the 11 strata using probability proportional to the number of the students as a measure of size. The third step was selecting participants from each school and college based on the proportion of the size of each department. The fourth step was selecting participants from first to fifth-years based on the proportion to each year. Then, the final step was randomly selecting the first participant and systematically selecting the rest participants from each level and section of the study year.

\section{Measurements}

The survey questionnaire consisted of four parts: Demographic Characteristic Questionnaire: used to document variables including participants' sex, age, religion, ethnicity, marital status, current place of living, area where they grew up, level of the study years, family history of mental illness, and substance use.

Self-Reported Questionnaire (SRQ-20): It is a screening tool for mental distress developed by WHO [50]. SRQ-20 is a self-report instrument with 20 binary responses (yes/no) questions. It has the potential of detecting cases and non-cases with sensitivity ranging from 63 to 90 and specificity ranging from 44 to 95 [51]. WHO recommends SRQ-20 as a reliable and valid instrument to detect general Common Mental Disorders [51]. It was developed specifically for use in LMICs [50]. SRQ-20 has been previously translated into Amharic language in Ethiopia, locally validated [52, 53], and used in different community [54-56] and institution-based surveys [24, $25,32,57$ ] with cut-off points $\geq 4$ [57], $\geq 7$ [25], $\geq 8$ [32] and $\geq 11$ [24]. SRQ-20 has good psychometric properties (i.e. sensitivity $86 \%$ and specificity $84 \%$ ) for detecting individuals with mental distress in the Ethiopian population with an optimal cut-off point at $\geq 8$ [58]. To identify cases in the current study, a cut-off point of $>7$ was used based on a previous validation study of SRQ-20 in Ethiopia that resulted in good sensitivity and specificity using a cut-off point of 8 [58]. The pilot data collected from 38 undergraduate students in a similar population but in a different setting to the current study showed that the internal consistency of SRQ-20 was 0.77.
The Perceived Need for Professional Mental Health Care Questionnaire: Used to assess the perceived need for professional mental health services in the past 3 months. It has been used in the previous studies [59, 60]. The question is phrased as follows: 'Was there a time when you thought you should see a doctor, counselor or other health professionals for your mental distress, but you did not go in the past three months?' with the response options of Yes/No. "Yes" response implies the perceived need for mental health care but not received in the past 3 months, whereas "No" response implies no need for mental health care for mental distress. Therefore, the perceived need for professional mental health care in this study implies the number of students who reported "Yes" option.

Barriers to Access to Care Evaluation (BACE-III): BACE was originally developed to identify barriers to receive professional mental health service for people with mental health problems [61]. It has 30 items to be completed by the participant (self-complete measure). This instrument has good psychometric properties (i.e. validity, reliability, and acceptability) [61]. BACE-III has three dimensions of potential barriers of stigma (12 items), attitudinal (10 items) and instrumental (8 items) related. This instrument asks about a range of issues that have ever stopped, delayed or discouraged an individual from receiving professional care for a mental health problem in the past 3 months. The response scale ranges from 0 (not at all) to 3 (a lot); the higher score indicating a greater barrier. Five of the thirty items contain a fifth option: "Not applicable". Findings for each barrier are presented in three ways: mean score for the item, barrier to any degree (the percentage of answering 1,2 or 3 ) or major barrier (the percentage of answering 3 ) based on BACE-III manual for researchers.

For the current study, BACE-III was translated into the Amharic language by two Amharic language experts whose first language is Amharic and their second language is English. One expert who knows the subject matter translated the instrument based on the BACE-III translation guide. The masked back-translation was made by two English language experts and one mental health expert. The research team compared the backtranslated instrument with the original version of BACEIII and agreed upon the consistency of the translation. The translated BACE-III was piloted on 40 undergraduate students in a similar population but in a different area of the current study setting. Its internal consistency was 0.85 .

After the pilot study, the authors examined the applicability of each question in the university set-up and noticed that item number 27 and 28 need some modifications. Discussion was made with a mental health expert who has experience of adapting mental 
health instruments. Then, question number 27 which says 'difficulty taking time off work' was modified as 'difficulty taking time off education' and question number 28 which says 'concern about what people at work might think, say or do', was modified as 'concern about what students might think, say or do'. The final version of the instrument was administered to students who scored $>7$ on the SRQ-20 and who had a need (those who answered "Yes") to receive professional mental care in the past 3 months of the study period. The internal consistency of the overall BACE-III scale after the revision was 0.85 , whereas for stigma sub-scale $=0.83$; attitudinal sub-scale $=0.67$ and instrumental sub-scale $=0.60$. Those participants who answered "No" for the perceived need for mental health care measuring questionnaire were asked 'In the past three months, did you receive help from a psychologist, doctors, friends, family, religious leaders or traditional healers?' by skipping the BACE-III questionnaire. See supplementary file 1.

Training of data collectors and data collection procedures Classroom representatives served as data collectors. A half day training was given by the principal investigator to data collectors about the aim of the research, the contents of data collection tools, how to approach participants, ethical issues, and responsibility of controlling missing data. The classroom representatives both males and females were contacted by the researcher through the help of their department heads, because they had cell phone numbers of each classroom representative. Then, with the assistance of the classroom representatives, the student participants came to the selected lecture halls and classrooms and the data collectors explained the aim of the study. Finally, after verbal agreement was received, the data collectors started to collect the data by explaining the instructions of all questionnaires with the close supervision of the principal investigator. To protect the confidentiality of the participants, personal identifiers were not included in the questionnaires; instead, a code was applied.

The data collection was carried out before the students' final examination to control for an inflation of the prevalence of mental distress. Those who scored $>7$ on SRQ-20 were asked to answer the questions about the perceived need for professional mental health care and then answer questions in the BACE-III questionnaire. Participants who answered "No" the question about the perceived need for professional mental health care skipped the BACE-III and answered why they did not need mental health treatment in the past 3 months. Finally, after the participants completed the selfadministered questionnaires, the data collectors immediately checked the existence of incomplete and missed information before the participants left the room.

\section{Data analysis}

Data cleaning and cross-checking were done before analysis using Statistical Packages for the Social Sciences (SPSS version 20). Descriptive statistical measures (i.e. percentage, frequency, mean, and standard deviation) were employed to summarize demographic characteristics of the participants and to identify barriers to mental health care services. Pearson chi-square test was used to examine the association between demographic variables with mental health care seeking intention and with the five most commonly reported barriers to receive mental health services. Furthermore, multiple linear regression was also used to model the association between demographic variables with a mean score of BACE-III subscales. Univariate regression analysis was used to identify potential candidate variables for multivariable linear regression with a $p$-value of $<0.2$ by referring previous published articles $[62,63]$. Then, further analysis was carried out using multivariable linear regression. The result was reported as being statistically significant whenever the p-value is less than 0.05 .

\section{Ethical considerations}

Ethical clearance for the conduct of the study was obtained from the Institutional Review Board (IRB) of Addis Ababa University College of Health Sciences. Information sheet containing details of the research and rights of the participants was attached to the questionnaire. Oral informed consent was obtained from the participants after we explained to them the purpose of the study, the participation was voluntary, and personal identifiers were not included in the questionnaires. Finally, the obtained data were kept anonymous and confidential during all stages of the research.

\section{Results}

Demographic characteristics

A total of 980 undergraduate students completed the screening phase survey from the sample of 1135 students approached, yielding $86.34 \%$ response rate. One third (34.6\%) of the participants had scored $>7$ on SRQ-20. The majority $(60.5 \%)$ were male. The age of the participants ranged from 17 to 38 years with a mean age of 21.53 years $(\mathrm{SD}=2.42)$. The participants were from diverse ethnic groups, the majority were from Amhara (34.6\%) and Wolaita (20.9\%) ethnic groups. Regarding marital status, $82.8 \%$ were single and $95.3 \%$ were living in the campus. Over half (54.7\%) were from urban backgrounds. First-year, second-year, and third-year undergraduate students took 27.7, 26.6, and $25.9 \%$ of the sample, respectively (Table 1 ). 
Table 1 Demographic characteristics of the study sample

\begin{tabular}{|c|c|c|c|}
\hline Variables & Total Sample (n) \% N (980) & $\begin{array}{l}\text { Screened positive for } \\
\text { mental distress (n) \% N (339) }\end{array}$ & $\begin{array}{l}\text { Participants with mental distress who have } \\
\text { not received formal Mental Care \% N (239) }\end{array}$ \\
\hline \multicolumn{4}{|l|}{ Sex } \\
\hline Male & $593(60.5)$ & $176(51.9)$ & $127(53.1)$ \\
\hline Female & $387(39.5)$ & $163(48.1)$ & $112(46.9)$ \\
\hline \multicolumn{4}{|l|}{ Age } \\
\hline Mean & 21.53 & 21.21 & 21.22 \\
\hline SD & 2.42 & 1.95 & 1.82 \\
\hline Minimum & 17 & 18 & 18 \\
\hline Maximum & 38 & 30 & 28 \\
\hline \multicolumn{4}{|l|}{ Religion } \\
\hline Christian Orthodox & $543(55.4)$ & $241(71.1)$ & $164(68.6)$ \\
\hline Christian Protestant & $330(33.7)$ & $50(17.7)$ & $46(19.2)$ \\
\hline Islam & $80(8.2)$ & $30(8.8)$ & $22(9.2)$ \\
\hline Christian Catholic & $8(0.8)$ & $2(0.6)$ & $2(0.8)$ \\
\hline No religion & $8(0.8)$ & $4(1.2)$ & $3(1.3)$ \\
\hline Others & $11(1.1)$ & $2(0.6)$ & $2(0.8)$ \\
\hline \multicolumn{4}{|l|}{ Ethnicity } \\
\hline Amhara & $339(34.6)$ & $164(48.4)$ & $110(46.0)$ \\
\hline Oromo & $155(15.8)$ & $58(17.1)$ & $41(17.2)$ \\
\hline Wolaita & $205(20.9)$ & $44(13)$ & $35(14.6)$ \\
\hline Gurage & $80(8.2)$ & $24(7.1)$ & $15(6.3)$ \\
\hline Tigre & $24(2.4)$ & $11(3.2)$ & $8(3.3)$ \\
\hline Sidama & $58(5.9)$ & $9(2.7)$ & $7(2.9)$ \\
\hline Hadiya & $32(3.3)$ & $8(2.4)$ & $6(2.5)$ \\
\hline Gamogofa & $30(3.1)$ & $8(2.4)$ & $6(2.5)$ \\
\hline Others & $57(5.7)$ & $13(3.9)$ & $11(4.6)$ \\
\hline \multicolumn{4}{|l|}{ Marital status } \\
\hline Single & $811(82.8)$ & $268(79.1)$ & $194(81.2)$ \\
\hline In a relation & $114(11.6)$ & $50(14.7)$ & $31(13.0)$ \\
\hline Married but not living together & $35(3.6)$ & $11(3.2)$ & $9(3.8)$ \\
\hline Divorced & $14(1.4)$ & $7(2.1)$ & $3(1.3)$ \\
\hline Married and living together & $6(0.6)$ & $3(0.9)$ & $2(0.2)$ \\
\hline \multicolumn{4}{|l|}{ Residence } \\
\hline In Campus & $934(95.3)$ & $320(94.4)$ & $223(93.3)$ \\
\hline Off Campus & $20(2)$ & $8(2.4)$ & $7(2.9)$ \\
\hline Both & $26(2.7)$ & $11(3.2)$ & $9(3.8)$ \\
\hline \multicolumn{4}{|l|}{ Area of growing } \\
\hline Urban & $536(54.7)$ & $176(51.9)$ & $127(53.1)$ \\
\hline Rural & $444(45.3)$ & $163(48.1)$ & $112(46.9)$ \\
\hline \multicolumn{4}{|l|}{ Level of study year } \\
\hline First-year & $271(27.7)$ & $117(34.5)$ & $81(33.9)$ \\
\hline Second-year & $261(26.6)$ & $85(25.1)$ & $58(24.3)$ \\
\hline Third-year & $254(25.9)$ & $84(24.8$ & $67(28.0)$ \\
\hline Fourth-year & $96(9.8)$ & $28(8.3)$ & $18(7.5)$ \\
\hline
\end{tabular}


Table 1 Demographic characteristics of the study sample (Continued)

\begin{tabular}{llll}
\hline Variables & Total Sample $(n) \%$ N (980) & $\begin{array}{l}\text { Screened positive for } \\
\text { mental distress (n) \% N (339) }\end{array}$ & $\begin{array}{l}\text { Participants with mental distress who have } \\
\text { not received formal Mental Care \% N (239) }\end{array}$ \\
\hline $\begin{array}{l}\text { Fifth-year } \\
\text { Family history of mental illness }\end{array}$ & $98(10.0)$ & $25(7.4)$ & $15(6.3)$ \\
Yes & $67(6.8)$ & $34(10.0)$ & $22(9.2)$ \\
No & $913(93.2)$ & $305(90.0)$ & $217(90.8)$ \\
Substance use & & $39(11.5)$ & $31(13.0)$ \\
Yes & $58(5.9)$ & $300(88.5)$ & $208(87)$ \\
No & $922(94.1)$ & & \\
\hline
\end{tabular}

\section{Mental distress}

The prevalence of mental distress was $34.6 \%$, indicated by 339 participants with SRQ-20 scored higher than 7. It was slightly higher (51.9\%) among male students. The item-based response of the study participants to the SRQ-20 is summarized in Fig. 1. The top three frequently reported symptoms were: loss of interest in things (37.60\%), being tired (36.90), and thought of ending one's life (36.80\%). The least reported symptom was handshaking/hand trembling (19.7\%).

\section{Perceived need for professional mental health care}

Of 339 participants with elevated symptoms of mental distress, $70.5 \%(n=239)$ reported a perceived need for professional mental health care in the past 3 months. The remaining $29.5 \%$ did not report a need for professional mental health treatment, because they have received the service from informal sources $(25.5 \%$ from religious leaders, friends, family, and traditional healers) and formal sources (4\% from doctors and psychologists). There was no significant gender difference in seeking mental health service, $\mathrm{X}^{2}(1)=0.48, p=0.49$. Likewise, there were no significant differences among the remaining demographic variables in those seeking mental health services (Table 2).

\section{Barriers to receive professional mental health care for mental distress}

Of the 339 participants who screened positive for mental distress, 239 (127 male and 112 female) had not received mental health services in the past 3 months, because of the barriers to receive the treatment, although they desired mental health care as indicated in Table 3. This table shows mean scores of an individual item, standard

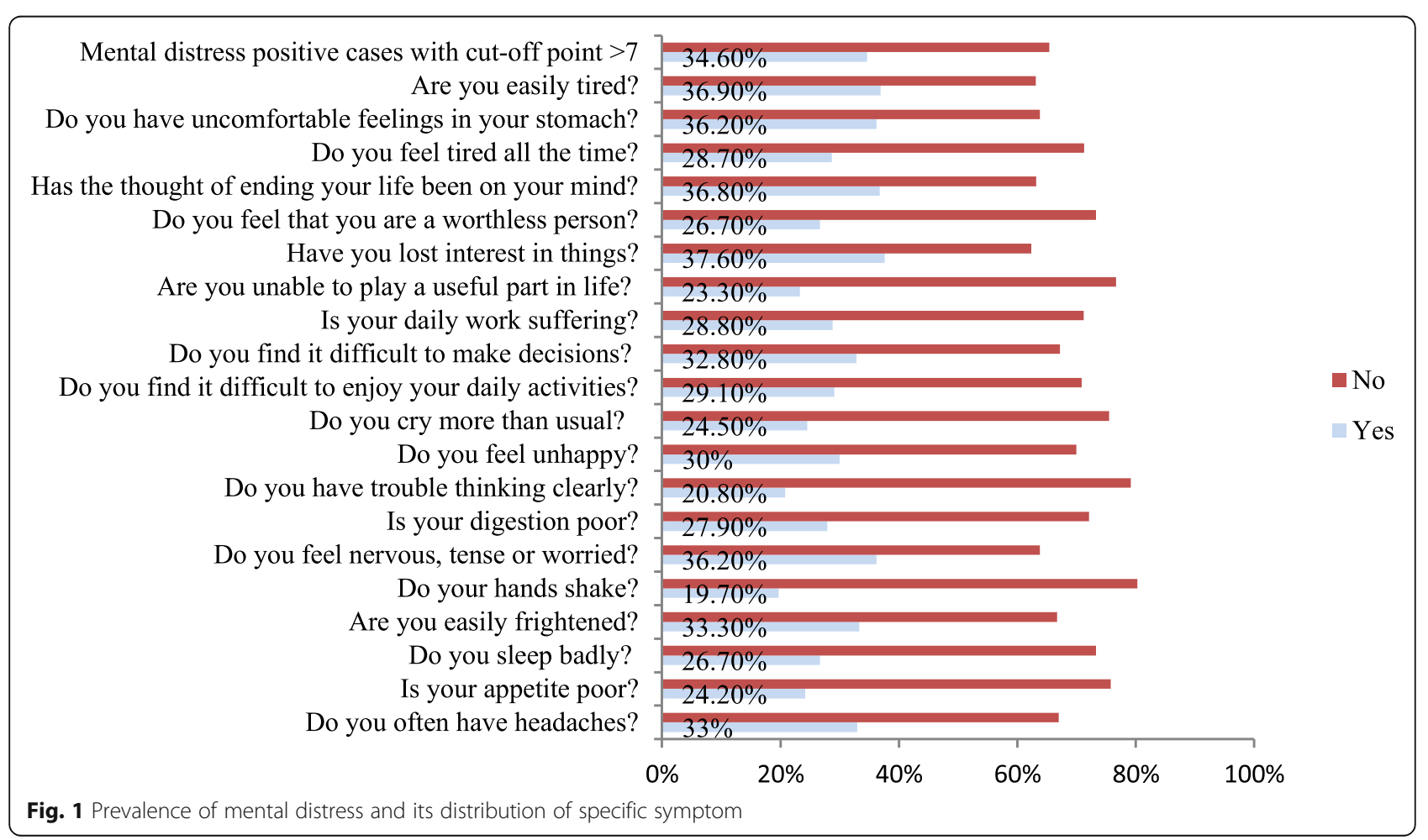


Table 2 The association between demographic variables and perceived need for professional mental health care

\begin{tabular}{|c|c|}
\hline Variables & $\begin{array}{l}\text { Need fo } \\
\text { health }\end{array}$ \\
\hline & Yes $(n)$ \\
\hline
\end{tabular}

Sex

$\begin{array}{lllll}\text { Female } & 112 & 51 & 0.48 & 0.49 \\ \text { Male } & 127 & 49 & & \\ \text { Religion } & & & & \\ \text { Orthodox } & 164 & 77 & 0.39 \\ \text { Protestant } & 46 & 14 & & \\ \text { Muslim } & 22 & 8 & & \\ \text { Others } & 7 & 1 & 3.77 & 0.88 \\ \text { Ethnicity } & & & & \\ \text { Amhara } & 111 & 53 & & \\ \text { Oromo } & 41 & 17 & & \\ \text { Wolaita } & 35 & 9 & & \\ \text { Gurage } & 15 & 9 & & \\ \text { Hadiya } & 6 & 2 & & \\ \text { Tigre } & 8 & 2 & \end{array}$

Marital status

\begin{tabular}{|c|c|c|c|c|}
\hline Single & 193 & 75 & 6.83 & 0.15 \\
\hline In a relationship & 31 & 19 & & \\
\hline Married but no living together & 2 & 1 & & \\
\hline Divorced & 10 & 1 & & \\
\hline Married and living together & 3 & 4 & & \\
\hline \multicolumn{5}{|l|}{ Residence } \\
\hline In campus & 223 & 97 & 1.89 & 0.39 \\
\hline Off campus & 7 & 1 & & \\
\hline Both & 9 & 2 & & \\
\hline \multicolumn{5}{|l|}{ Area of growing } \\
\hline Rural & 112 & 51 & 0.48 & 0.49 \\
\hline Urban & 127 & 49 & & \\
\hline \multicolumn{5}{|l|}{ Level of study year } \\
\hline First-year & 81 & 36 & 5.61 & 0.23 \\
\hline Second-year & 58 & 27 & & \\
\hline Third-year & 67 & 17 & & \\
\hline Fourth-year & 18 & 10 & & \\
\hline Fifth-year & 15 & 10 & & \\
\hline \multicolumn{5}{|l|}{ Family history of mental illness } \\
\hline No & 217 & 88 & 0.61 & 0.44 \\
\hline Yes & 22 & 12 & & \\
\hline \multicolumn{5}{|l|}{ Substance use } \\
\hline No & 208 & 92 & 1.71 & 0.19 \\
\hline Yes & 31 & 8 & & \\
\hline
\end{tabular}

deviation, percentage to any degree, and major barriers to receive mental health care. There were top five barriers to receiving mental health care the reported percentage was greater than $60 \%$ to any degree (sum of responses of a little, quite a lot, and a lot).

The first barrier to seeking mental health care was 'thinking the problem would get better by itself' reported by $74.4 \%$ to any degree and $37 \%$ thought that it would act as a major barrier to receive mental health services. The second was 'being unsure where to go to get professional care' which accounted for $71.6 \%$ to any degree and $21 \%$ reported as a major barrier. The third was 'wanting to solve the problem on their own', whereby $71 \%$ of the participants reported this as a barrier to any degree and $28 \%$ thought that it would act as a major barrier to receiving mental health care. The fourth was 'denying a mental health problem', where $67.4 \%$ of the participants reported this as a barrier to any degree and $38 \%$ reported it as a major barrier. The fifth was 'preferring to get alternative forms of care' reported as any degree of the barrier by $67 \%$, while $34 \%$ of the participants reported it as a major barrier to receiving mental health service. Of all the demographic variables, only a family history of mental illness had a significant association, $\mathrm{X}^{2}$ $[3]=14.48=p=0.01$ with 'denying mental health problem' of the top five barriers. See supplementary file 2 .

Of the top five barriers, the top four were attitudinal related barriers to receiving professional mental health services. The fifth, 'being unsure of where to get professional care' was an instrumental-related sub-scale of BACE-III. As a result of, the mean score of attitudinal related barriers sub-scale of BACE-III $(M=1.26, \mathrm{SD}=$ $0.68)$ was the highest when compared with instrumental related barriers sub-scale $(M=0.78, \quad S D=0.43)$ and stigma related barriers sub-scale $(\mathrm{M}=0.61, \mathrm{SD}=0.65)$ of BACE-III.

\section{Predictors of attitudinal related barriers to receive professional mental health care}

In univariate regression analysis (Table 4), fourth-year students perceived significantly more attitudinal related barriers $(\beta=0.27 ; 95 \% \mathrm{CI}=0.24,1.16 ; p=0.003)$ than the fifth-year students. Multivariable analysis also showed that only fourth-year students perceived significantly more attitudinal related barriers $(\beta=0.27 ; 95 \% \mathrm{CI}=0.21$, $1.14 ; p=0.01)$ than the fifth-year students.

\section{Predictors of instrumental related barriers to receive professional mental health care}

In univariate regression analysis (Table 5), female students perceived significantly fewer instrumental related barriers $(\beta=-.15 ; 95 \% \mathrm{CI}=-.24,-.02 ; p=0.02)$ than male students. Students from rural background perceived significantly more instrumental related barriers 
$(\beta=0.18 ; 95 \% \mathrm{CI}=0.04,0.26 ; p=0.01)$ than students from urban background. Fourth-year students perceived significantly more instrumental related barriers $(\beta=0.28$; $95 \% \mathrm{CI}=0.17,0.76 ; p=0.002$ ) than the fifth-year students. Students who reported a family history of mental illness perceived significantly more instrumental related barriers $(\beta=0.16 ; 95 \% \mathrm{CI}=0.05,0.43 ; \mathrm{p}=0.01)$ than students who reported no family history of mental illness. Students who reported substance use perceived significantly more instrumental related barriers $(\beta=0.15$; $95 \% \mathrm{CI}=0.03,0.36 ; p=0.02)$ than students who reported no substance use. A 1 year increase in age was associated with 0.19 unit increased in instrumental related barriers to receiving mental health services $(\beta=0.19$; $95 \% \mathrm{CI}=0.02,0.07 ; p=0.004)$. In multivariable analysis, students from rural background perceived significantly more instrumental related barriers $(\beta=0.16 ; 95 \% \mathrm{CI}=$ $0.03,0.25 ; p=0.01)$ than students from urban background. Besides this, second-year $(\beta=0.27 ; 95 \% \mathrm{CI}=0.02$, $0.52 ; p=0.03)$ and fourth-year students $(\beta=0.29$; $95 \% \mathrm{CI}=0.19,0.77 ; p=0.001)$ perceived significantly more instrumental related barriers than the fifth-year students.

\section{Predictors of stigma related barriers to receive professional mental health care}

Univariate regression analysis showed that students from rural background perceived significantly more stigma related barriers $(\beta=0.13 ; 95 \% \mathrm{CI}=0.00,0.33 ; p=0.05)$ than students from urban background. Students who reported a history of mental illness in the family perceived significantly more stigma related barriers $(\beta=0.13 ; 95 \% \mathrm{CI}=$ $0.01,0.57 ; \mathrm{p}=0.05)$ than students who reported no family history of mental illness. Students who reported substance use perceived significantly more stigma related barriers $(\beta=0.13 ; 95 \% \mathrm{CI}=.00,0.49 ; \mathrm{p}=0.05)$ than students who reported no substance use. A 1 year increase in age was associated 0.17 unit increased in stigmarelated barriers to mental health services $(\beta=0.17$; $95 \% \mathrm{CI}=0.02,0.10 ; p=0.01)$. In multivariable analysis, only fourth-year students perceived significantly more stigma related barriers $(\beta=0.24 ; 95 \% \mathrm{CI}=0.14,1.01 ; \mathrm{p}=$ 0.01) than the fifth-year students (Table 6).

\section{Discussion}

In this study, there is high prevalence of mental distress and perceived need for professional mental health care services among university students. The top five frequently reported barriers to receive professional mental health service were: thinking the problem would get better by itself, being unsure where to go to get professional care, wanting to solve the problem by oneself, denying a mental health problem, and preferring to get alternative forms of care. Having a rural background, being a second and fourth-year student, and a family history of mental illness were significantly associated with barriers to receive professional mental health service.

The prevalence of mental distress which is reported in the present study is higher than what has been reported in the meta-analysis of the general population studies in Ethiopia [14]. Perhaps our finding is not surprising, because university students are more likely than the general population to be exposed to mental stress [21]. The possible difference between individual studies reviewed in the meta-analysis [14] and the present study could be partly attributed to the discrepancy in data collection instrument with cut-off points used, age group, and setting. The data collection tools used in the most individual article within the meta-analysis study were ICD-10, PHQ-9, EPDS, K10, HADS etc. with different cut-off points, but in our study we have used SRQ-20 that might be one cause for the discrepancy. The other was a difference in age group and setting, where young person experience higher mental distress compared with adults in the general population.

The current prevalence of mental distress is higher than that reported in previous studies conducted among university students $[24,64]$. One possible reason for the discrepancy is the difference in the cut-off values used to define mental illness $[24,64]$. The other explanation for the difference is other studies did not use locally validated instrument [64]. On the other hand, the present finding is lower than what was reported in previous studies in Ethiopian universities $[35,65]$. The first possible justification for the difference might be data collection tool being used to screen mental distress [35, 65]. The second possible reason for the difference could be the timing of the data collection, where our data collected prior to the approaching final examinations. The present finding is comparable with a study report conducted in Jima University [66]. This might be resulted from similarity of the data collection tool and the cut-off points used to define mental distress.

The high prevalence of perceived need for professional mental health services in the current study suggests that most students with mental distress in Wolaita Sodo University remain untreated. This may not be surprising, because most universities in LMICs are ill-equipped to provide services for students' mental health issues [47]. Previous study also reported only a few university students receive mental health services for their mental health problems as a result of lack of appropriate services [67]. Our finding is higher than previously reported in the general population of Ethiopia. For instance, a meta-analysis study reported that the pooled prevalence of the help-seeking intention of people with depression in Ethiopia is 42\% [17], which is much lower than the current finding. The possible explanations for the 
Table 3 Barriers to receiving professional mental health care among students with mental distress who have not received mental care in the past three months $(n=239)$

\begin{tabular}{|c|c|c|c|c|}
\hline \multirow[t]{2}{*}{ Barriers to Mental Health Care } & \multicolumn{2}{|c|}{$\begin{array}{l}\text { Mental Distress who did not receive } \\
\text { professional mental health treatment }(N=239)\end{array}$} & \multirow[t]{2}{*}{$\begin{array}{l}\text { Total } \\
(\mathrm{N})\end{array}$} & \multirow[t]{2}{*}{$\begin{array}{l}\text { Item Mean } \\
\text { and (SD) }\end{array}$} \\
\hline & $\begin{array}{l}\text { Barrier to any } \\
\text { degree } \%(n)\end{array}$ & $\begin{array}{l}\text { Major barrier } \\
\%(n)\end{array}$ & & \\
\hline \multicolumn{5}{|l|}{ Stigma-related barriers } \\
\hline Concern about what my family might think, say, do or feel & $48.1(115)$ & $18.4(44)$ & 239 & $0.98(1.18)$ \\
\hline $\begin{array}{l}\text { Concern that I might be seen as weak for having a mental } \\
\text { health problem }\end{array}$ & $38.9(93)$ & $14.2(34)$ & 239 & $0.76(1.10)$ \\
\hline Feeling embarrassed or ashamed & $29.8(71)$ & $10.9(26)$ & 239 & $0.58(1.01)$ \\
\hline Concern that I might be seen as 'crazy' & $31.9(76)$ & $10.5(25)$ & 239 & $0.61(1.02)$ \\
\hline Not wanting a mental health problem to be on my medical records & $26.0(62)$ & $8.4(20)$ & 239 & $0.50(0.95)$ \\
\hline $\begin{array}{l}\text { Concern that people might not take me seriously if they found } \\
\text { out I was having professional care }\end{array}$ & $28.0(67)$ & $7.1(17)$ & 239 & $0.51(0.93)$ \\
\hline Concern that people I know might find out & $28.4(68)$ & $6.7(16)$ & 239 & $0.47(0.87)$ \\
\hline Concern about what my friends might think, say or do & $33.5(80)$ & $6.7(16)$ & 239 & $0.56(0.92)$ \\
\hline Concern about what students might think, say or do & $31.4(75)$ & $6.3(15)$ & 239 & $0.53(0.90)$ \\
\hline \multicolumn{5}{|l|}{ Attitudinal-related barriers } \\
\hline Thinking I did not have a problem & $67.4(161)$ & $38.1(91)$ & 239 & $1.59(1.29)$ \\
\hline Thinking the problem would get better by itself & $74.4(178)$ & $36.8(88)$ & 239 & $1.65(1.22)$ \\
\hline Preferring to get alternative forms of care & $66.5(159)$ & $34.3(82)$ & 239 & $1.51(1.27)$ \\
\hline Wanting to solve the problem on my own & $71.1(170)$ & $28.0(67)$ & 239 & $1.50(1.18)$ \\
\hline Preferring to get help from family or friends & $58.6(140)$ & $22.2(53)$ & 239 & $1.20(1.20)$ \\
\hline Dislike of talking about my feelings, emotions or thoughts & $38.0(91)$ & $9.6(23)$ & 239 & $0.69(1.02)$ \\
\hline Concerns about the treatments available (e.g. medication side effects) & $36.8(88)$ & $9.6(23)$ & 239 & $0.65(1.01)$ \\
\hline Thinking that professional care probably would not help & $30.9(74)$ & $7.5(18)$ & 239 & $0.54(0.93)$ \\
\hline Fear of being put in hospital against my will & $21.4(51)$ & $7.1(17)$ & 239 & $0.41(0.89)$ \\
\hline $\begin{array}{l}\text { Having had previous bad experiences with professional } \\
\text { care for mental health }\end{array}$ & $16.7(40)$ & $4.6(11)$ & 239 & $0.30(0.76)$ \\
\hline \multicolumn{5}{|l|}{ Instrumental-related barriers } \\
\hline Not being able to afford the financial costs involved & $56.0(134)$ & $25.5(61)$ & 239 & $1.23(1.25)$ \\
\hline Having no one who could help me get professional care & $59.8(143)$ & $24.7(59)$ & 239 & $1.26(1.22)$ \\
\hline Being unsure where to go to get professional care & $71.6(171)$ & $21.0(51)$ & 239 & $1.36(1.11)$ \\
\hline Difficulty taking time off education & $55.2(132)$ & $17.6(42)$ & 239 & $1.10(1.16)$ \\
\hline Problems with transport or travelling to appointments & $44.4(106)$ & $17.6(42)$ & 239 & $0.92(1.18)$ \\
\hline Being too unwell to ask for help & $51.9(124)$ & $14.6(35)$ & 239 & $0.96(1.11)$ \\
\hline Professionals from my own ethnic or cultural group not being available & $26.4(63)$ & $6.7(16)$ & 239 & $0.47(0.89)$ \\
\hline
\end{tabular}

Note: Question number 5, 14, 24, and 29 in the BACE-III were not included in this table, because more than $97 \%$ of the participants responded "Not applicable" option for each item. Barriers reported percentage greater than $60 \%$ to any degree were indicated in bold color

difference could be a difference in mental health literacy, study population and the data collection instruments being used. Moreover, our study supports the previous web-based survey reporting that 37 to $84 \%$ of university students screened positive to mental distress did not receive any professional mental health service [34]. The similarity of the result may be due to using similar data collection tool and similar age group of participants.
Among the top five reported barriers to receive professional mental health service by the students who recognized a need for care, the first was thinking mental distress would get better by itself. This indicates that students perceive mental distress would get better without receiving any treatment, which may be associated with considering mental health problems as less serious so they are reluctant to use available mental health 
Table 4 Predictors of attitudinal related barriers to receiving professional mental health care in univariate and multivariable linear regression $(n=239)$

\begin{tabular}{|c|c|c|c|c|c|c|}
\hline \multirow[t]{3}{*}{ Variables } & \multicolumn{6}{|c|}{ Attitudinal related barriers } \\
\hline & \multicolumn{3}{|c|}{ Univariate } & \multicolumn{3}{|c|}{ Multivariable } \\
\hline & Beta & $95 \% \mathrm{Cl}$ & $P$-value & Beta & $95 \% \mathrm{Cl}$ & $P$-value \\
\hline Age & .09 & $-.02, .08$ & .18 & .01 & $-.05, .06$ & .91 \\
\hline \multicolumn{7}{|c|}{ Level of study years } \\
\hline First year & .01 & $-.36, .38$ & .97 & 01 & $-.41, .42$ & .97 \\
\hline Second year & .03 & $-.33, .43$ & .80 & .03 & $-.35, .46$ & .81 \\
\hline Third Year & .11 & $-.20, .54$ & .37 & .12 & $-.21, .57$ & .37 \\
\hline Fourth Year & .27 & $.24,1.16$ & .003 & .26 & $.21,1.14$ & .004 \\
\hline Fifth Year (Ref.) & - & $.80,1.48$ & $<0.01$ & & & \\
\hline \multicolumn{7}{|c|}{ Family mental illness history } \\
\hline No (Ref.) & - & $1.14,1.32$ & $<0.01$ & & & \\
\hline Yes & .12 & $-.01, .59$ & .06 & .11 & $-.04, .56$ & .09 \\
\hline R2 & & & & 0.08 & & \\
\hline
\end{tabular}

Table 5 Predictors of instrumental related barriers to receiving professional mental health care in univariate and multivariable linear regression $(n=239)$

\begin{tabular}{|c|c|c|c|c|c|c|}
\hline \multirow[t]{3}{*}{ Variables } & \multicolumn{6}{|c|}{ Instrumental related barriers } \\
\hline & \multicolumn{3}{|c|}{ Univariate } & \multicolumn{3}{|c|}{ Multivariable } \\
\hline & Beta & $95 \% \mathrm{Cl}$ & P-value & Beta & $95 \% \mathrm{Cl}$ & $P$-value \\
\hline \multicolumn{7}{|l|}{ Sex } \\
\hline Male (Ref.) & - & $.77, .92$ & $<0.01$ & & & \\
\hline Female & -.15 & $-.24,-.02$ & .02 & -.10 & $-.20, .02$ & .12 \\
\hline Age & .19 & $.02, .07$ & .004 & .13 & $-.01, .07$ & .09 \\
\hline \multicolumn{7}{|l|}{ Area of growing } \\
\hline Urban (Ref.) & & $.64, .78$ & $<0.01$ & & . & \\
\hline Rural & .18 & $.04, .26$ & .01 & .16 & $.03, .25$ & .01 \\
\hline \multicolumn{7}{|c|}{ Level of study years } \\
\hline First year & .11 & $-.13, .34$ & .39 & .23 & $-.05, .47$ & .11 \\
\hline Second year & .14 & $-.10, .39$ & .25 & .27 & $.02, .52$ & .03 \\
\hline Third Year & .14 & $-.10, .37$ & .27 & .23 & $-.02, .47$ & .07 \\
\hline Fourth Year & .28 & $.17, .76$ & .002 & .29 & $.19, .77$ & .001 \\
\hline Fifth Year (Ref.) & & $.42, .86$ & $<0.01$ & & & \\
\hline \multicolumn{7}{|c|}{ Family mental illness history } \\
\hline No (Ref.) & & $.70, .82$ & $<0.01$ & & & \\
\hline Yes & .16 & $.05, .43$ & .01 & .09 & $-.05, .32$ & .15 \\
\hline \multicolumn{7}{|l|}{ Substance use } \\
\hline No (Ref.) & & $.70, .82$ & $<0.01$ & & & \\
\hline Yes & .15 & $.03, .36$ & .02 & .09 & $-.05, .28$ & .17 \\
\hline R2 & & & & 0.14 & & \\
\hline
\end{tabular}

Note. Reference category for multivariable: $\beta=-.16 ; 95 \% \mathrm{Cl}=-1.02,0.70$ $p=.72$. Ref. refers to reference category for univariate regression analysis and $\mathrm{Cl}$ Confidence Interval for $\beta$
Table 6 Predictors of stigma related barriers to receiving professional mental health care in univariate and multivariable linear regression $(n=239)$

\begin{tabular}{|c|c|c|c|c|c|c|}
\hline \multirow[t]{3}{*}{ Variables } & \multicolumn{6}{|c|}{ Stigma related barriers } \\
\hline & \multicolumn{3}{|c|}{ Univariate } & \multicolumn{3}{|c|}{ Multivariable } \\
\hline & Beta & $95 \% \mathrm{Cl}$ & P-value & Beta & $95 \% \mathrm{Cl}$ & $P$-value \\
\hline Age & .17 & $.01, .10$ & .01 & .10 & $-.02, .09$ & .19 \\
\hline \multicolumn{7}{|l|}{ Area of growing } \\
\hline Urban (Ref.) & & $.42, .65$ & $<0.01$ & & & \\
\hline Rural & .13 & $.00, .33$ & .05 & .12 & $-.02, .32$ & .08 \\
\hline \multicolumn{7}{|l|}{ Level of study years } \\
\hline First year & .02 & $-.32, .37$ & .89 & .11 & $-.25, .54$ & .47 \\
\hline Second year & -.002 & $-.36, .36$ & .99 & .08 & $-.26, .50$ & .54 \\
\hline Third Year & .13 & $-.18, .54$ & .32 & .18 & $-.11, .63$ & .16 \\
\hline Fourth Year & .24 & $.14,1.01$ & .01 & .24 & $.14,1.02$ & .01 \\
\hline Fifth Year (Ref.) & - & $.19, .83$ & $<0.01$ & & & \\
\hline \multicolumn{7}{|c|}{ Family mental illness history } \\
\hline No (Ref.) & - & $.50, .67$ & $<0.01$ & & & \\
\hline Yes & .13 & $.01, .57$ & .05 & .09 & $-.09,-.48$ & .19 \\
\hline \multicolumn{7}{|l|}{ Substance use } \\
\hline No (Ref.) & & $.49, .67$ & $<0.01$ & & & \\
\hline Yes & .13 & $.00, .49$ & .05 & .07 & $-.12, .39$ & .31 \\
\hline R2 & & & & 0.10 & & \\
\hline
\end{tabular}

Note. Reference category for multivariable: $\beta$ : $-.45 ; 95 \% \mathrm{Cl}=-1.72$ to $.83 ; \mathrm{p}=$ 0.49 . Ref. refers to reference category for univariate regression analysis and $\mathrm{Cl}$ Confidence Interval for $\beta$

services [68] and it may also be associated with having poor mental health literacy [69]. The current finding supports a prior study reporting that the majority of college students believed that time by itself would solve their mental health problem [59].

Lack of information where to go to get professional care was reported as the second barrier to receiving mental health service in the University. However, WSU has two counseling offices and a teaching referral hospital that aim to provide mental health services for students with mental health problems. This information gap is probably caused by a lack of awareness creation of these services by the mental health service providers. Our finding is supported by prior studies, where the majority of university students had no information about the availability of mental health service in their university [70, 71].

Wanting to solve mental health problems by oneself is reported as the third common barrier to receive mental health service in the present study. This suggests that most students may not want to share their mental health problems with professionals preferring to handle the problem by themselves. This is possibly due to perceiving their problem as not serious or transitory, being skeptical about the effectiveness of professional mental 
health service, fear of stigma, and privacy issue [34]. As a result, they might prefer to manage their mental health problem alone perhaps utilizing both positive and negative strategies such as problem-solving [72], substance uses, and isolation [73] as examples. The present finding supports past studies reporting a major barrier to receiving formal mental health service among university students with mild to moderate depression and anxiety is preferring to self-medicate [74, 75].

The fourth barrier identified in the present study is denying mental health problems. Students may not want to recognize their mental health problems due to lack of knowledge about mental illness [69] or they may deny their mental health problem as a coping strategy by rejecting reality and not taking appropriate action to treat their problem [73]. Our finding support a prior study finding reporting that the majority of university students deny mental health problems which hindered them from receiving mental health care [37]. Furthermore, the present study interestingly showed that a family history of mental illness significantly associated with a student denying mental distress. This could be due to students had negative experiences by being with individual with mental illness previously so that they could deny their illness as a coping mechanism [45].

The fifth commonly reported barrier for using mental health service is preferring to get mental health service from informal sources. This suggests that majority of the students receive mental health help from friends, family, relatives, religious leaders, and traditional healers [35], which is also common practice in the general population of Ethiopia [76]. The present finding is also supported by previous studies, where informal sources of mental health care reported by college students was cited as a reason for not receiving mental health services at their university $[69,77]$.

Interestingly, the current study found that fourth-year students with mental distress are more likely than fifthyear students to report attitudinal, instrumental, and stigma related treatment barriers. Since, the majority of the fourth- and fifth-years students in the present study were from the engineering department, the possible difference could be resulted from as the level of study year/ age increases, students become more stable and have better mental health literacy [78, 79]. In this sense, fourth-year students might encounter more barriers to receiving mental health care compared to fifth-year students. However, our finding contradicts a study finding first-year students are more likely than their third-year and senior students to perceive a greater number of barriers to receiving mental health care [37]. The result difference with the present study possibly due to the difference in the data collection tool, study setting, and sample size in each level of the study year. Caution in the present study, the number of the fourth-year students was small.

Our study also found that students from rural backgrounds are more likely than students from urban backgrounds to face instrumental related barriers to access professional mental health care. This might be because of young person from rural areas may not have a knowledge of mental illnesses so that they may not have sufficient information about the availability of free mental health services in the university and they may not be psychologically open toward professional mental health services [80]. Our finding compare positively with a study conducted in Australia reporting that adolescents from rural areas have more instrumental related challenges for receiving formal mental health care than adolescents from urban areas [81]. Our study also shows that second-year students reported more instrumentalrelated barriers compared with fifth-year students. This was probably due to the interaction effects of other controlled variables in the adjusted model. This may need further study in the future.

The present study implies that mental distress is prevalent among undergraduate students. Likewise, the need for mental health services is increasing, even though the students are not be able to receive the service provided in the university. This was because of attitudinal, instrumental and stigma-related barriers. Particularly, fourth-year students and students from rural background were more likely to report these barriers compared with fifth-year and students from urban backgrounds, respectively. This indicates to a need for designing practical mental health interventions to treat students' mental distress, to alleviate their psychological suffering and minimize the effect on their academic work, general and social functioning [29]. Therefore, the present findings provide useful information and directions for university mental health service providers to create awareness about mental health problems and their service, the benefits of receiving mental health care, and when and where to seek mental health services by distributing flyers, preparing training, and mental health day. All these together enhance to develop active university-based mental health intervention to reduce the prevalence of mental distress and to satisfy the need for receiving mental health service by minimizing the reported major barriers.

Any research has its own limitations; similarly, the present study is not limitation free. First, data were collected using self-reported questionnaires so that recalling bias may occur for mental distress symptoms that happened in the past 1 month and rating the degree of barriers to mental health care may also difficult to remember. Second, the barriers to the provision of mental health care measuring instrument was not locally 
adapted, although it was properly translated and piloted for the present research. Third, a screening tool was used to identify participants positive for mental distress; it would have been better to use a diagnosis tool. Fourth, data collectors were classroom representatives, so that they were in a position to know the participants' response to each item while checking missing on the questionnaires. Fifth, since the participants were recruited from a single public university, it is difficult to generalize the result to all public universities and private colleges that are found in Ethiopia. Finally, students who received treatment from the informal sources should have to complete BACE-III to understand whether they were aware of their needs for professional care or not, but we did not do that.

Further, future research is needed to study barriers to receiving professional mental health care among students with mental distress who do not wish to receive mental health care from professionals as a result of receiving treatment from informal sources. Additionally, the present study has also investigated some demographic predictors of barriers to receive mental health care, but further study is necessary to examine the associations of other variables such as mental health literacy and academic results with barriers to receive mental health services. Despite the limitations mentioned above, the present study has some strengths. First, a large number of students participated in the prevalence study. Second, the study used a locally adapted instrument, SRQ20. Third, the research contains findings of the prevalence of mental distress, perceived needs, predictors, and barriers to receive professional mental health services together; all this information taken together can serve as input for future feasibility studies of mental health interventions for mental distress among university students.

\section{Conclusions}

There is high prevalence of mental distress and perceived need for professional mental health service among undergraduate students at Wolaita Sodo University that identify the need for professional mental health interventions. Mental health providers in the university should make their services accessible to the students and promote the service for better utilization. Besides the interventions, developing preventive mental health education strategies is essential to address the prevalence of mental distress with the creation of conducive environments that promote and sustain positive mental health for every student. Moreover, preparing for the celebration of mental health day in the university can play a role in changing the attitude of students toward mental health care and improving mental health literacy, because out of the five major barriers, four of them were attitudinal related. In this celebration day, creating awareness about the treatment of mental distress like any other physical illness can be emphasized, as well as the benefits of receiving mental health care from professionals, recognizing mental distress in the early stages, and educating students to seek mental health care from professionals in parallel with receiving treatment from alternative sources. Therefore, this paper is a call for action from university administrations, university mental health care providers, and the Ministry of Science and Higher Education for helping undergraduate students with mental distress and to work to minimizing mental health distress on campus.

\section{Supplementary information}

Supplementary information accompanies this paper at https://doi.org/10. 1186/s12888-020-02602-3.

Additional file 1. Instruments used for data collection.

Additional file 2. The association between demographic variables and common barriers to receive professional mental health care.

\section{Abbreviations}

BACE: Barriers to Access to Care Evaluation; LMICs: Low- and Middle- Income Countries; SNNPR: Southern Nations, Nationalities, and Peoples' Region; SRQ: Self-Reported Questionnaire; SPSS: Statistical Packages for Social Sciences; M: Mean; SD: Standard Deviation; WHO: World Health Organization; WSU: Wolaita Sodo University; ICD-10: International Classification of Diseases 10th edition; PHQ-9: Patient Health Questionnaire; EPDS: Edinburgh Postnatal Depression Scale; K10: Kessler Psychological/Mental Distress Scale;

HADS: Hospital Anxiety and Depression Scale

\section{Acknowledgements}

We want to thank research participants for their active participation and time. We would also like to acknowledge Addis Ababa University and Wolaita Sodo University for funding and material support. Lastly, we would like to thank Sisay Abayneh, Aklilu Abera, Dagim Degissew, and Dr. Clare Pain for editing the manuscript.

\section{Authors' contributions}

AN led to conceiving the study, supervision of data collection, developed study design, data analysis, interpretation of the findings, drafted manuscript and revised the manuscript for submission in consultation with co-authors. MAK contributed to data analysis, commenting on all drafts of the manuscripts, interpretation of the findings, and feedback. GM contributed to data analysis, commenting on all drafts of the manuscripts, interpretation of the findings, and feedback. DW was involved in data analysis, commenting on all drafts of the manuscripts, interpretation of the findings, and feedback. MA led to conceiving the study, data analysis, commenting on all drafts of the manuscripts, interpretation of the findings, and feedback. All co-authors have approved the final version of the manuscript.

\section{Funding}

This research is funded by Addis Ababa University and Wolaita Sodo University. These funders had no role in the study design; data collection, analysis and interpretation of data; in writing the manuscript; and in the decision to submit the paper for publication.

Availability of data and materials

The datasets used and/or analyzed during the current study are available from the corresponding author on reasonable request.

Ethics approval and consent to participate

Ethical clearance approval obtained from the Institutional Review Board (IRB) of Addis Ababa University College of Health Sciences. Respondents took part in the study after providing oral consent. Data kept anonymous and 
confidential during all stages of the research process. Protocol number: 045/ 17/Psych. Oral consent was approved by the IRB.

\section{Consent for publication}

Not applicable.

\section{Competing interests}

The authors declare that they have no competing interests.

Received: 12 July 2019 Accepted: 14 April 2020

Published online: 25 April 2020

\section{References}

1. Patel V, Hanlon C. Where there is no psychiatrist, vol. 3. London: RCPsych Publications; 2018

2. Mirowsky J, Ross CE. Measurement for a human science. J Health Soc Behav. 2002;43(2):152-70

3. Drapeau A, Marchand A, Beaulieu-Prévost D. Epidemiology of psychological distress. Mental illnesses understanding, prediction and control; 2012. https://doi.org/10.5772/30872.

4. Auerbach RP, Mortier P, Bruffaerts R, Alonso J, Benjet C, Cuijpers P, WHO WMH-ICS Collaborators. Mental disorder risk profiles in the World Health Organization World Mental Health Surveys International College Student Project. Int J Methods Psychiatr Res. 2018;10:e1752.

5. World Health Organization. Depression and other common mental disorders, global health estimates. 2017.

6. Lund C, Breen A, Flisher AJ, Kakuma R, Corrigall J, Joska JA, Swartz L, Patel V. Poverty and common mental disorders in low and middle income countries: a systematic review. Soc Sci Med. 2010;71(3):517-28.

7. Demyttenaere K, Bruffaerts R, Posada-Villa J, Gasquet I, Kovess V, Lepine J, Angermeyer MC, Bernert SD, Morosini P, Polidori G, Kikkawa T. Prevalence, severity, and unmet need for treatment of mental disorders in the World Health Organization world mental health surveys. Jama. 2004;291(21):2581-90.

8. Patel V. Mental health in low-and middle-income countries. Br Med Bull. 2007:81(1):81-96.

9. Sorsdahl KR, Flisher AJ, Wilson Z, Stein DJ. Explanatory models of mental disorders and treatment practices among traditional healers in Mpumulanga, South Africa. Afr J Psychiatry. 2010;13(4):284-90.

10. Saxena S, Thornicroft G, Knapp M, Whiteford $H$. Resources for mental health: scarcity, inequity, and inefficiency. Lancet. 2007 Sep 8;370(9590):878-89.

11. Hanlon C, Alem A, Lund C, Hailemariam D, Assefa E, Giorgis TW, Chisholm D. Moving towards universal health coverage for mental disorders in Ethiopia. Int J Ment Heal Syst. 2019;13(1):11.

12. Girma E, Tesfaye M. Patterns of treatment seeking behavior for mental illnesses in Southwest Ethiopia: a hospital based study. BMC psychiatry. 2011;11(1):138.

13. Lund C, Tomlinson M, De Silva M, Fekadu A, Shidhaye $R$, Jordans $M$, Petersen I, Bhana A, Kigozi F, Prince M, Thornicroft G. PRIME: a programme to reduce the treatment gap for mental disorders in five low-andmiddleincome countries. PLoS Med. 2012;9(12):e1001359.

14. Kassa GM, Abajobir AA. Prevalence of common mental illnesses in Ethiopia: a systematic review and meta-analysis. Neurol Psychiatry Brain Res. 2018;30: 74-85.

15. Jebena MG, Lindstrom D, Belachew T, Hadley C, Lachat C, Verstraeten R, De Cock N, Kolsteren P. Food insecurity and common mental disorders among Ethiopian youth: structural equation modeling. PLoS One. 2016;11(11): e0165931.

16. Bitew T. Prevalence and risk factors of depression in Ethiopia: a review. Ethiop J Health Sci. 2014;24(2):161-9.

17. Bifftu BB, Takele WW, Guracho YD, Yehualashet FA. Depression and its help seeking behaviors: a systematic review and meta-analysis of community survey in Ethiopia. Depress Res Treat. 2018;2018:1-11.

18. Bekele YY, Flisher AJ, Alem A, Baheretebeb Y. Pathways to psychiatric care in Ethiopia. Psychol Med. 2009;39(3):475-83.

19. Federal Democratic Republic of Ethiopia Ministry of Health. National mental health strategy, 2012/13-2015/16. Addis Ababa: Federal Ministry of Health; 2012.

20. Federal Democratic Republic of Ethiopia Ministry of Health. Health secto transformation plan: 2015/2016-2019/2020. Addis Ababa: FMOH; 2015.

21. Stallman HM. Psychological distress in university students: a comparison with general population data. Aust Psychol. 2010;45(4):249-57.
22. Steptoe A, Tsuda A, Tanaka Y. Depressive symptoms, socio-economic background, sense of control, and cultural factors in university students from 23 countries. Int J Behav Med. 2007;14(2):97-107.

23. Lun K, Chan CK, Ip P, Ma S, Tsai WW, Wong CS, Wong CH, Wong TW, Yan D. Depression and anxiety among university students in Hong Kong. Hong Kong Med J. 2018;24(5):466-72

24. Dessie Y, Ebrahim J, Awoke T. Mental distress among university students in Ethiopia: a cross sectional survey. Pan Afr Med J. 2013;15(1):95.

25. Tesfaye A. Prevalence and correlates of mental distress among regular undergraduate students of Hawassa University: a cross sectional survey. East Afr J Public Health. 2009;6(1):85-94.

26. Mackean G. Mental health and well-being in post-secondary education settings. Canada: Citeseer; 2011.

27. Kaya M, Genc M, Kaya B, Pehlivan E. Prevalence of depressive symptoms, ways of coping, and related factors among medical school and health services higher education students. Turk Psikiyatri Dergisi. 2007;18(2):137.

28. Gress-Smith JL, Roubinov DS, Andreotti C, Compas BE, Luecken LJ. Prevalence, severity and risk factors for depressive symptoms and insomnia in college undergraduates. Stress Health. 2015;31(1):63-70.

29. Field T, Diego M, Pelaez M, Deeds O, Delgado J. Depression and related problems in university students. Coll Stud J. 2012:46(1):193-203.

30. Ryan ML, Shochet IM, Stallman HM. Universal online interventions might engage psychologically distressed university students who are unlikely to seek formal help. Adv Ment Health. 2010;9(1):73-83.

31. Tesfahunegn TB, Gebremariam EH. Mental distress and associated factors among Aksum University students, Ethiopia: a cross-sectional study. BMC psychiatry. 2019;19(1):71.

32. Dachew BA, Bisetegn TA, Gebremariam RB. Prevalence of mental distress and associated factors among undergraduate students of University of Gondar, Northwest Ethiopia: a cross-sectional institutional based study. PLoS One. 2015;10(3):e0119464.

33. Andrews $B$, Wilding JM. The relation of depression and anxiety to life-stress and achievement in students. Br J Psychol. 2004;95(4):509-21.

34. Eisenberg D, Golberstein E, Gollust SE. Help-seeking and access to mental health care in a university student population. Med Care. 2007;45(7):594-601.

35. Gebreegziabher $Y$, Girma E, Tesfaye M. Help-seeking behavior of Jimma university students with common mental disorders: a cross-sectional study. PLoS One. 2019:14(2):e0212657.

36. Hinderaker DJ. College student mental health and use of counseling center services; 2013.

37. Vidourek RA, King KA, Nabors LA, Merianos AL. Students' benefits and barriers to mental health help-seeking. Health Psychol Behav Med. 2014;2(1):1009-22.

38. Heath PJ, Vogel DL, Al-Darmaki FR. Help-seeking attitudes of United Arab Emirates students: examining loss of face, stigma, and self-disclosure. Couns Psychol. 2016;44(3):331-52

39. van Zoonen K, Kleiboer A, Cuijpers P, Smit J, Penninx B, Verhaak P, Beekman A. Determinants of attitudes towards professional mental health care, informal help and self-reliance in people with subclinical depression. Int J Soc Psychiatry. 2016;62(1):8493.

40. Al-Darmaki FR. Attitudes towards seeking professional psychological help: what really counts for United Arab Emirates university students? Soc Behav Personal Int J. 2003;31(5):497-508.

41. Luitel NP, Jordans MJ, Kohrt BA, Rathod SD, Komproe $\mathbb{H}$. Treatment gap and barriers for mental health care: a cross sectional community survey in Nepal. PloS one. 2017;12(8):e0183223.

42. Masuda A, Anderson PL, Edmonds J. Help-seeking attitudes, mental health stigma, and self-concealment among African American college students. J Black Stud. 2012;43(7):773-86.

43. Rodriguez ML, Corse AK, Rosen LD. Mental health services use among medical students: perceived stigma and barriers to care. Med Sci Educ. 2017;27(2):267-72.

44. Sareth K, Dang HM, Weiss B. Predictors of Mental Health Help Seeking Among Cambodian Adolescents; 2019.

45. Lally J, ó Conghaile A, Quigley S, Bainbridge E, McDonald C. Stigma of mental illness and help-seeking intention in university students. Psychiatrist. 2013:37(8):253-60

46. Ruiz P. In: Sadock BJ, Sadock VA, editors. Comprehensive textbook of psychiatry. Philadelphia: lippincott Williams \& wilkins; 2000

47. Evans-Lacko S, Thornicroft G. WHO world mental health surveys international college student initiative: implementation issues in low-and middle-income countries. Int J Methods Psychiatr Res. 2019;28(2):e1756. 
48. Asante $\mathrm{KO}$, AndohAthur J. Prevalence and determinants of depressive symptoms among univerity students in Ghana J Affect Disord 2015;171:161-6.

49. Shamsuddin K, Fadzil F, Ismail WS, Shah SA, Omar K, Muhammad NA, Jaffar A, Ismail A, Mahadevan R. Correlates of depression, anxiety and stress among Malaysian university students. Asian J Psychiatr. 2013;6(4):318-23.

50. van der Westhuizen C, Wyatt G, Williams JK, Stein DJ, Sorsdahl K. Validation of the self reporting questionnaire 20-item (SRQ-20) for use in a low-and middle-income country emergency Centre setting. Int J Ment Heal Addict. 2016;14(1):37-48.

51. Beusenberg M, Orley JH, World Health Organization. A User's guide to the self reporting questionnaire (SRQ). Geneva: World Health Organization; 1994.

52. Hanlon C, Medhin G, Alem A, Araya M, Abdulahi A, Hughes M, Tesfaye M, Wondimagegn D, Patel V, Prince M. Detecting perinatal common mental disorders in Ethiopia: validation of the self-reporting questionnaire and Edinburgh postnatal depression scale. J Affect Disord. 2008;108(3):251-62.

53. Kortmann F, Ten Horn S. Comprehension and motivation in responses to a psychiatric screening instrument validity of the SRQ in Ethiopia. $\mathrm{Br}$ J Psychiatry. 1988;153(1):95-101.

54. Alem A, Kebede D, Woldesemiat G, Jacobsson L, Kullgren $G$. The prevalence and socio-demographic correlates of mental distress in Butajira, Ethiopia. Acta Psychiatr Scand. 1999;100:48-55.

55. Yimam K, Kebede Y, Azale T. Prevalence of common mental disorders and associated factors among adults in Kombolcha town, Northeast Ethiopia. J Depress Anxiety S. 2014;1:2167-1044.

56. Mekonnen E, Esayas S. Correlates of mental distress in Jimma town, Ethiopia. Ethiop J Health Sci. 2003;13(1).

57. Alem A, Araya M, Melaku Z, Wendimagegn D, Abdulahi A. Mental distress in medical students of Addis Ababa University. Ethiop Med J. 2005:43(3):159-66.

58. Youngmann R, Zilber N, Workneh F, Giel R. Adapting the SRQ for Ethiopian populations: a culturally-sensitive psychiatric screening instrument. Transcult Psychiatry. 2008;45(4):566-89.

59. Czyz EK, Horwitz AG, Eisenberg D, Kramer A, King CA. Self-reported barriers to professional help seeking among college students at elevated risk for suicide. J Am Coll Heal. 2013;61(7):398-406.

60. Eisenberg D, Speer N, Hunt JB. Attitudes and beliefs about treatment among college students with untreated mental health problems. Psychiatr Serv. 2012;63(7):711-3.

61. Clement S, Brohan E, Jeffery D, Henderson C, Hatch SL, Thornicroft G. Development and psychometric properties the barriers to access to care evaluation scale (BACE) related to people with mental ill health. BMC Psychiatry. 2012;12(1):36.

62. Shumet S, Azale T, Ayano G, Abebaw D, Amare T, Getnet W. Intention to seek help for depression and associated factors among residents of Aykel town, Northwest Ethiopia: cross-sectional study. Int J Ment Heal Syst. 2019; 13(1):18.

63. Choueiry G, Salameh P. Automating data analysis in epidemiology. J Data Sci. 2019;17(1):55-80.

64. Hersi L, Tesfay K, Gesesew H, Krahl W, Ereg D, Tesfaye M. Mental distress and associated factors among undergraduate students at the University of Hargeisa, Somaliland: a cross-sectional study. Int J Ment Heal Syst. 2017; 11(1):39.

65. Haile YG, Alemu SM, Habtewold TD. Common mental disorder and its association with academic performance among Debre Berhan University students, Ethiopia. Int J Ment Heal Syst. 2017;11(1):34.

66. Kerebih $\mathrm{H}$, Ajaeb $\mathrm{M}$, Hailesilassie $\mathrm{H}$. Common mental disorders among medical students in Jimma University, Southwest Ethiopia. Afr Health Sci. 2017;17(3):844-51.

67. Kim JE, Saw A, Zane N. The influence of psychological symptoms on mental health literacy of college students. Am J Orthopsychiatry. 2015;85(6):620.

68. Li W. University students' mental health help-seeking: intention and service use (doctoral dissertation); 2016.

69. Amarasuriya SD, Jorm AF, Reavley NJ. Depression literacy of undergraduates in a non-western developing context: the case of Sri Lanka. BMC research notes. 2015;8(1):593.

70. Menon V, Sarkar S, Kumar S. Barriers to healthcare seeking among medical students: a cross sectional study from South India. Postgrad Med J. 2015 91(1079):477-82

71. Afolabi MO, Daropale VO, Irinoye Al, Adegoke AA. Health-seeking behaviour and student perception of health care services in a university community in Nigeria. Health. 2013;5(05):817.
72. Ajibade BL, Olabisi OO, Fabiyi B, Ajao $\bigcirc$, Ayeni AR. Stress, types of stressors and coping strategies amongst selected nursing schools students in southwest, Nigeria. Eur J Biol Med Sci Res. 2016;4(3):1-5.

73. Deasy C, Coughlan B, Pironom J, Jourdan D, Mannix-McNamara P. Psychological distress and coping amongst higher education students: a mixed method enquiry. PLoS One. 2014;9(12):e115193.

74. Arria AM, Winick ER, Garnier-Dykstra LM, Vincent KB, Caldeira KM, Wilcox HC, O'Grady KE. Help seeking and mental health service utilization among college students with a history of suicide ideation. Psychiatr Serv. 2011; 62(12):1510-3.

75. Sheppard R, Deane FP, Ciarrochi J. Unmet need for professional mental health care among adolescents with high psychological distress. Austr N Z J Psychiatry. 2018;52(1):59-67.

76. Kerebih $\mathrm{H}$, Abera M, Soboka M. Pattern of help seeking behavior for common mental disorders among urban residents in Southwest Ethiopia. Qual Prim Care. 2017;25(4):208-16.

77. Bilican Fl. Help-seeking attitudes and behaviors regarding mental health among Turkish college students. Int J Ment Health. 2013;42(2-3):43-59.

78. Bayram N, Bilgel N. The prevalence and socio-demographic correlations of depression, anxiety and stress among a group of university students. Soc Psychiatry Psychiatr Epidemiol. 2008;43(8):667-72.

79. Furnham A, Cook R, Martin N, Batey M. Mental health literacy among university students. J Public Mental Health. 2011;10(4):198-210.

80. Braun B. Barriers to mental health access for rural residents. In: Maryland Family Policy Impact Seminar, vol. 18; 2003. p. 2008.

81. Quine S, Bernard D, Booth M, Kang M, Usherwood T, Alperstein G, Bennett D. Health and access issues among Australian adolescents: a rural-urban comparison. Rural Remote Health. 2003;3(3):245.

\section{Publisher's Note}

Springer Nature remains neutral with regard to jurisdictional claims in published maps and institutional affiliations.

Ready to submit your research? Choose BMC and benefit from

- fast, convenient online submission

- thorough peer review by experienced researchers in your field

- rapid publication on acceptance

- support for research data, including large and complex data types

- gold Open Access which fosters wider collaboration and increased citations

- maximum visibility for your research: over $100 \mathrm{M}$ website views per year

At BMC, research is always in progress.

Learn more biomedcentral.com/submissions 